Markov A. V. Development of gingivitis in rats receiving oral applications of peroxide sunflower oil. Journal of Education, Health and Sport. 2020;10(6):334-340. eISSN 2391-8306. DOI http://dx.doi.org/10.12775/JEHS.2020.10.06.035

https://apcz.umk.pl/czasopisma/index.php/JEHS/article/view/JEHS.2020.10.06.035

https://zenodo.org/record/3924464

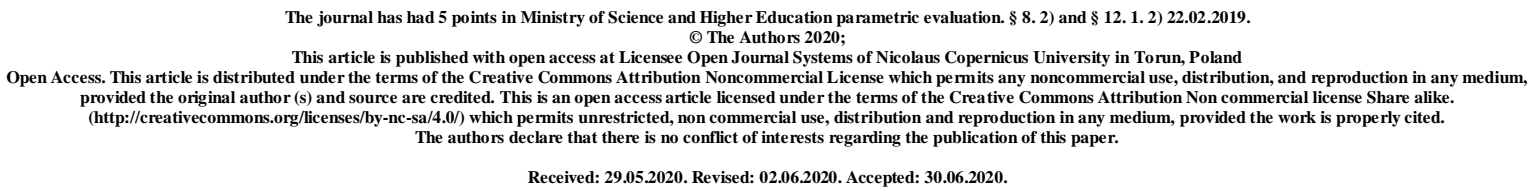

UDK 616.31:664.315:615.015

\title{
DEVELOPMENT OF GINGIVITIS IN RATS RECEIVING ORAL APPLICATIONS OF PEROXIDE SUNFLOWER OIL
}

\author{
A. V. Markov \\ Lviv National Medical University named after Danylo Galytskij
}

\section{Abstract}

Aim. Determine the condition of the gums in rats receiving oral applications of peroxide sunflower oil (PSO).

Methods. PSO was obtained by heating sunflower oil in the presence of $\mathrm{H}_{2} \mathrm{O}_{2}$ at $+180^{\circ} \mathrm{C}$ for 60 minutes. PSO in a dose of $0.5 \mathrm{ml}$ per rat was applied to the oral mucosa for 3 or 5 days. The activity of elastase, urease, lysozyme, catalase and the content of MDA (malondialdehyde) were determined in the gum. The antioxidant-prooxidant API index was calculated by the ratio of catalase and MDA, and the degree of dysbiosis was calculated by the ratio of the relative activities of urease and lysozyme..

Results. After 5 days of PSO applications, an increase in elastase activity, urease, MDA content and the degree of dysbiosis against the background of a decrease in lysozyme activity, catalase and the API index was established.

Conclusion. Oral applications of PSO cause a decrease in the level of non-specific immunity, antioxidant defense, an increase in microbial seeding, the degree of dysbiosis and the development of gingivitis.

Key words: periodontium; fat peroxidation; gingivitis; dysbiosis; lysozyme; antioxidant protection. 


\section{Introduction}

Recently, the use of thermal fat cooking has become significantly more widespread, the negative consequence of which is the formation of toxic peroxidation products [1-3].

The data of experimental researches in which the negative influence of peroxide sunflower oil (PSO) on a condition of fabrics of an oral cavity at its long introduction into an organism with a food are established $[4,5]$. The negative effect of PSO on the condition of other organs and tissues was noted: the mucous membrane of the colon [6] and the liver [7]. It is possible that the pathological processes that develop in the tissues of the oral cavity during the consumption of PSO are secondary, due to peroxide intoxication of other organs, including the liver, by the mechanisms of hepato-oral syndrome [8].

The aim of this work was to study the condition of the gums of rats after oral applications of PSO for a short period of research (3-5 days).

\section{Material and research methods}

PSO was obtained by heating unrefined sunflower oil at $+180^{\circ} \mathrm{C}$ in the presence of $1.5 \% \mathrm{H}_{2} \mathrm{O}_{2}$ (30\% solution) for 60 minutes.

The experiments were performed on 18 white Wistar rats (females, 4-5 months, live weight $210 \pm 12 \mathrm{~g}$ ). Animals received complete feed (Table). Applications of PSO to the oral mucosa $(\mathrm{OM})$ were made daily at a dose of $0.5 \mathrm{ml}$ per rat for three or five days. After euthanasia, gums were isolated and the level of markers of inflammation was determined in their homogenate [9]: elastase activity [10] and malonic dialdehyde (MDA) content [11], as well as the activity of antioxidant enzyme catalase [12], bacterial enzyme urease [13], activity lysozyme (one of the factors of nonspecific immunity) [14].

Table. The composition of feed for rats $(\%)$

\begin{tabular}{|l|c|}
\hline \multicolumn{1}{|c|}{ Component } & Content, \% \\
\hline Wheat grain is crushed & 80 \\
\hline Soybean meal & 15 \\
\hline Mineral mixture [18] & 4 \\
\hline Vitamin mixture [18] & 1 \\
\hline
\end{tabular}

According to the ratio of catalase activity and MDA content, the antioxidantprooxidant index of API was calculated [9], and according to the ratio of relative activities of urease and lysozyme, the degree of dysbiosis was calculated according to A. P. Levitsky [15]. 
The condition of peroxidation of PSO was determined in accordance with the recommendations [16].

The results of the experiments were subjected to standard statistical processing [17].

\section{Results and discussion}

Analysis of PSO peroxidation products showed that the content of dieneconjugates increased 6 times $(2.5 \mathrm{mmol} / 1$ in sunflower oil and $15 \mathrm{mmol} / 1 \mathrm{in}$ PSO), and the MDA content increased almost 14 times $(0.51 \mathrm{mmol} / 1$ in sunflower oil and $6.92 \mathrm{mmol} / 1$ in PSO).

In fig. 1 shows the level of biochemical markers of inflammation (elastase and MDA) in the gums of rats receiving oral applications of PSO. It is seen that after 3 days of application the activity of elastase increases by $27 \%$, and after 5 days - by $51 \%$. The content of MDA after 3 days of applications increases by $15 \%$ ( $>0.1$ ), and after 5 days - by $28 \%$ (p $<0.05)$.

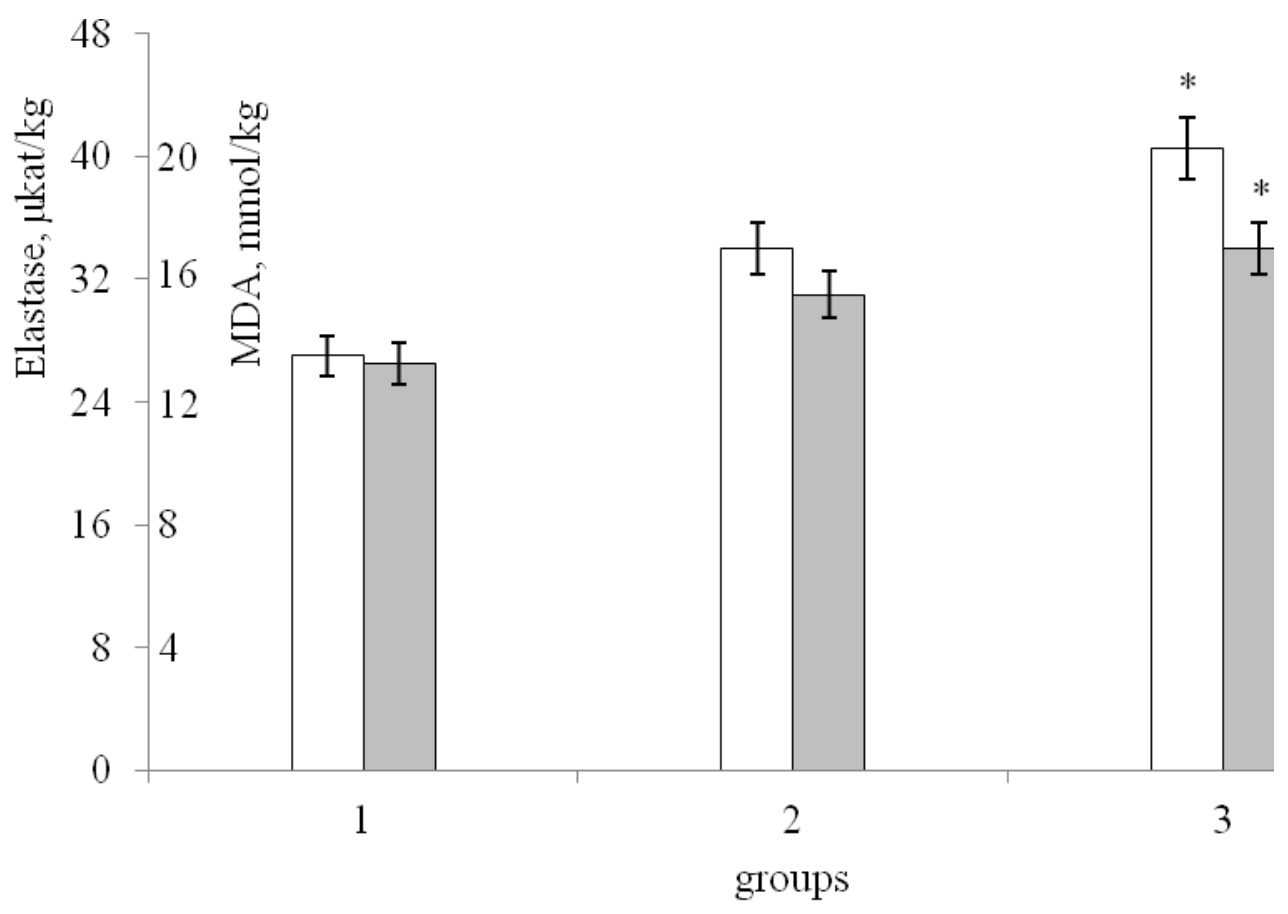

\section{$\square$ Flastase $\square \mathrm{MDA}$}

Fig. 1. The level of markers of inflammation in the gums of rats who received oral applications of PSO

( 1 - control; 2 - PSO, 3 days; 3 - PSO, 5 days $) *-p<0,05$ in comparison with gr. 1

The data obtained indicate that PSO applications cause the development of inflammatory-dystrophic process in the gums (i.e., gingivitis). 
In fig. 2 shows the effect of oral PSO applications on catalase activity and API index. As can be seen from these data, catalase activity after 3 days is reduced by $3 \%$ ( $p>0.05$ ), and after 5 days by $23 \%$ ( $\mathrm{p}<0.05$ ). The API index significantly decreases after 3 days of applications (by $21 \%$ ), and after 5 days by $39 \%$.

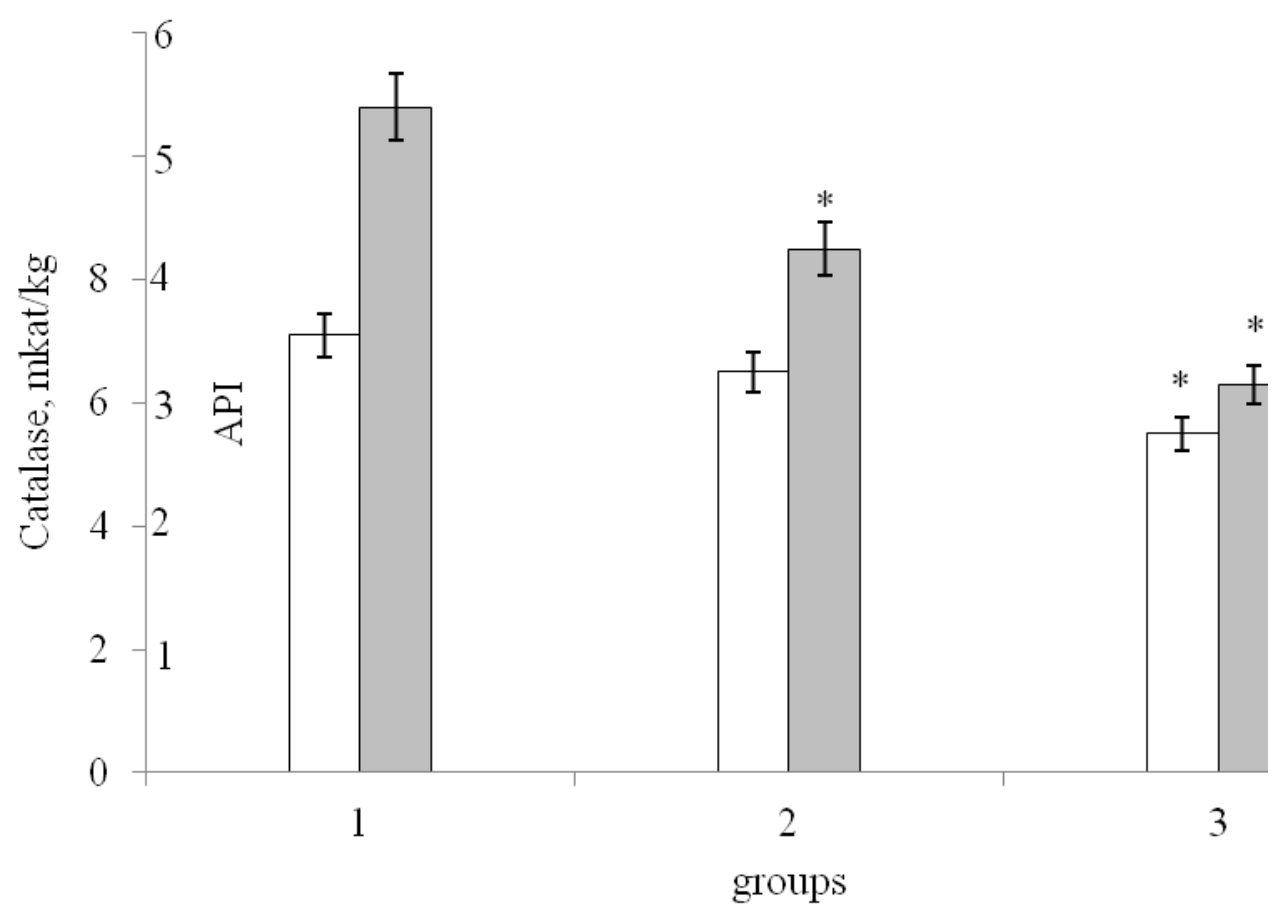

$\square$ Catalase $\square$ API

Fig. 2. Catalase activity and API index in the gums of rats receiving oral applications of PSO (1-3 - see Fig. 1) * $-\mathrm{p}<0.05$ compared with gr. 1

These data indicate the suppression of the antioxidant protection system of the periodontium under the influence of PSO.

In fig. 3 presents the results of determination in the gums of rats, which made oral applications of PSO, urease activity, lysozyme and the degree of dysbiosis. It is seen that urease activity significantly increases after 3 days of PSO applications (by 70\%), and after 5 days by $132 \%$. This indicates a significant increase in bacterial contamination of the gums of rats, which made applications of PSO.

Lysozyme activity, on the contrary, decreases after 3 days by $18 \%$ (however $\mathrm{p}>0.05$ ), and after 5 days decreases by $44 \%$ ( $\mathrm{p}<0.01$ ). The obtained data indicate a decrease in the level of nonspecific immunity in the periodontium of rats treated with PSO.

As a result, we have a significant increase in the degree of dysbiosis in the gums: after 3 days almost 2 times, and after 5 days - 4 times. 


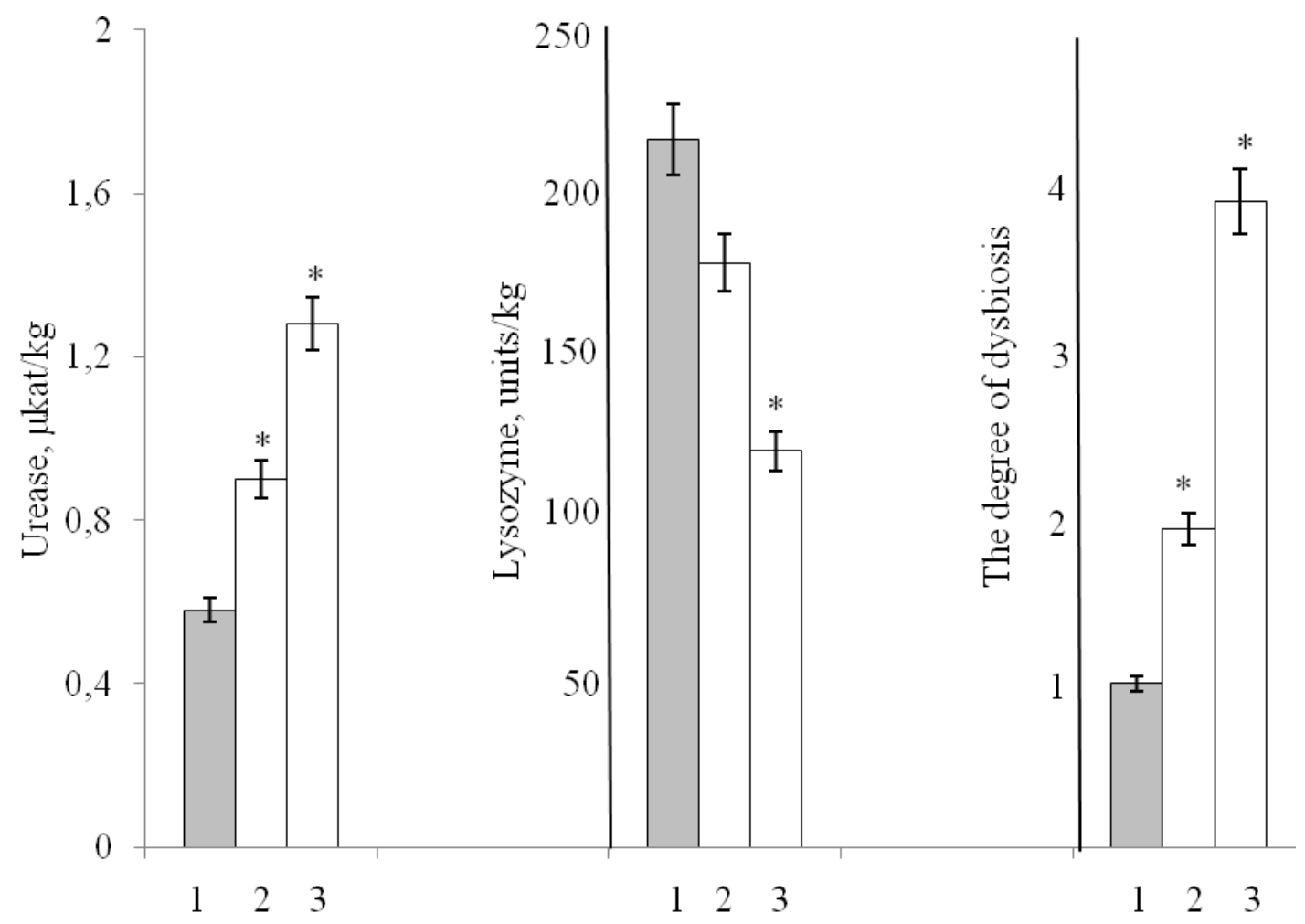

Fig. 3. The activity of urease, lysozyme and the degree of dysbiosis in the gums of rats who received oral applications of PSO (1-3 - see Fig. 1$) *-p<0,05$ compared with gr. 1

In a number of experimental works $[19,20]$ it was shown that the development of dental complications with long-term consumption of PSO can be prevented by the introduction of multifunctional means with food.

Given the results of this study, which showed the direct effect of toxic substances PSO on the condition of the periodontium, there is a need to use somatotropic antiperoxides (in the form of mucosa-adhesive gels or dental elixirs).

Unfortunately, it is very difficult to limit the consumption of thermally oxidized dietary fats to a large extent, given the conservatism of human taste preferences.

\section{Conclusions}

1. Oral applications of peroxide sunflower oil reduce the level of nonspecific immunity and antioxidant protection in the periodontium, resulting in the development of dysbiosis and inflammation.

2. To prevent dental complications when consuming thermally oxidized fats, it is necessary to limit their consumption or search for protective equipment. 


\section{References}

1. Levitsky AP, Potapova IL. Fatty food, fatty acids, Healthy sun-flower olive. Intern. Journ. Food a Nutrition sciences. 2015; 4(3): 15-20.

2. Levitsky AP. The pathophysiology of high-fat diet and ways to prevent its complications. Bulletin of XVII readings named after V. V. Podvysotsky, May 24-25, Odessa, 2018: 120-124. (in Russian)

3. Penumetcha M, Khan-Merihant N, Parthasarathy S. Enhanced solubilization and intestind absorption of cholesterol by oxidized linoleic acid. J. Lipid Res. 2002; 43(6): 895903.

4. Labush IuZ, Markov AV, Zubachik VM [and others]. Mucosoprotective effect of lysozyme-forte in rats that received super-oxidized sunflower. Bulletin of Marine Medicine. 2018; 2(79): 75-79. (in Ukrainian)

5. Markov AV. Effect of over-oxidized sunflower oil on the condition of periodontium of rats. Bulletin of Dentistry. 2018; 28(2(103): 14-17. (in Ukrainian)

6. Bocharov A. V. The influence of flavancontent means on gut mucosa state at rats received peroxide sunflower oil. Journal of Education, Health and Sport. 2018; 8(8): 12001205.

7. Vasyuk V. L. Hepatoprotective action of flavancontent means at hepatopathy, caused by the peroxide sunflower oil. Bulletin of Marine Medicine. 2018; 1: 101-104. (in Russian)

8. Levitsky AP, Demyanenko SA. Hepato-oral syndrome. Simferopol, Tarpan, 2012: 140. (in Russian)

9. Levitsky AP, Denga OV, Makarenko OA [and others]. Biochemical markers of inflammation of oral cavity tissue: method guidelines. Odessa, KP OGT, 2010: 16. (in Russian)

10. Levitsky AP, Stefanov AV. The methods of the determination of the activity of elastase and its inhibitors: method guidelines. Kiev, GFK, 2002:15. (in Russian)

11. Stalnaya ID., Garishvili TG. The method of revelation of malonic dialdehyde with thiobarbituric acid. Moskow, Medicine, 1977: 66-68. (in Russian)

12. Girin SV. The modification of the method of the determination of catalase activity in biological substrates. Laboratory diagnosis. 1999; 4:45-46. (in Russian)

13. Gavrikova LM, Segen IT. Urease activity of oral liquid in patients with acute odontogenic infection of maxillo-facial part. Stomatology. 1996; The extra issue :49-50. (in Russian) 
14. Levitsky AP. Lysozyme instead of antibiotics. Odessa, KP OGT, 2005: 74. (in Russian)

15. Levitsky AP, Makarenko OA, Denga OV [and others]. The experimental methods of restoration and estimation of the degree of dysbiosis in oral tissues. Bulletin of Dentistry. 2010; 2: 22-23. (in Russian)

16. Levitsky AP, Makarenko OA, Khodakov IV. Methods to investigate fats and oils. Odessa, KP OGT, 2015: 32. (in Russian)

17. Truhacheva NV. Mathematical Statistics in biomedical research using application package Statistica. Moskow, GJeOTAR-Media, 2012: 379. (in Russian)

18. Eggum B. Methods to evaluate utilization of proteins by animal. Moscow: Kolos, 1977: 189. (in Russian)

19. Markov AV, Labush IuZ, Zubachik VM [and others]. Therapeutic and preventive action flavan-containing antidisbiotic means on a mucose membrane of the oral cavity of the rats, received peroxide sunflower oil. Phytotherapy. Chasis. 2018; 2: 33-35. (in Ukrainian)

20. Levitsky AP, Makarenko OA, Selivanskaya IA [and others]. The experimental prophylaxis of the peroxide periodontitis by antidysbiotic means. Journal of Education, Health and Sport. 2017; 7(2): 682-693. 